\title{
Kontekstuele bepalers by die beplanning van skoolwoordeboeke
}

\author{
Herman L. Beyer, Departement Taal- en Literatuurstudie, Universiteit \\ van Namibië, Windhoek, Namibië (hbeyer@unam.na)
}

Opsomming: Die doel van hierdie artikel is om tot die metaleksikografiese gesprek oor skoolwoordeboeke as 'n tipe pedagogiese woordeboek by te dra. Die fokus is op kontekstuele bepalers wat by die beplanning van skoolwoordeboeke verreken behoort te word: Binne die konteks van ' $n$ veeltalige Namibië word enkele onderwyskundige sisteme verken wat 'n impak op die ontwerp van gedrukte skoolwoordeboeke vir die sekondêre skoolfase kan hê, naamlik skoolkurrikula, die nasionale taalbeleid vir skole en die beleid van leerdergerigte onderwys. Hierdie artikel voer ook aan dat die voor die hand liggende teikengebruiker van 'n skoolwoordeboek, naamlik die leerder, nie die enigste teikengebruiker is nie: Die onderwyser word as medeteikengebruiker gestel wanneer dit by die gebruik van woordeboeke in die onderrigleersituasie kom. Verskillende tipes gevalle van woordeboekgebruik in die mikrokonteks van die onderrigleersituasie word onderskei, naamlik woordeboekonderrig, woordeboekgeïntegreerde taalonderrig en woordeboekgeondersteunde taalonderrig. Hierdie tipes gebruik behoort komponente van 'n woordeboekpedagogie te wees, wat uiteindelik behoort te lei tot outonome woordeboekgebruik en die gepaardgaande vestiging van 'n individuele woordeboekkultuur by die leerder. Die leksikograaf moet al hierdie aspekte inreken wanneer 'n skoolwoordeboek beplan word ten einde die nodige leksikografiese vernuwing in te voer. Enkele voorstelle vir sodanige vernuwings en vir verdere navorsing word ten slotte aangebied.

Sleutelwoorde: GEBRUIKERSGERIGTE LEKSIKOGRAFIE, KONTEKS, LEERDER, LEERDERGERIGTE ONDERWYS, LEERWOORDEBOEK, LEKSIKOGRAAF, METALEKSIKOGRAFIE, NASLAANWOORDEBOEK, ONDERWYSER, PEDAGOGIESE WOORDEBOEK, SISTEEM, SKOOLWOORDEBOEK, TAALBELEID, TEIKENGEBRUIKER, WOORDEBOEKGEBRUIK, WOORDEBOEKGEÏNTEGREERDE TAALONDERRIG, WOORDEBOEKONDERSTEUNDE TAALONDERRIG, WOORDEBOEKONDERRIG, WOORDEBOEKPEDAGOGIE

\begin{abstract}
Contextual Determiners in the Planning of School Dictionaries. The aim of this article is to contribute to the metalexicographical discussion of school dictionaries. The focus is on contextual determiners that should be accounted for in the planning of school dictionaries: Within the context of a multilingual Namibia, some educational systems that could have an influence on the design of printed school dictionaries for the secondary school phase, i.e. school curricula, the national language policy for schools and the policy of learner-centred education, are explored. This article also argues that the obvious target user of a school dictionary, i.e. the learner, is not the only target user: The teacher is seen as co-target user when dictionary use takes place in the teaching learning situation. Different types of dictionary use instances can be distinguished in the micro-context of the teaching learning situation, i.e. dictionary skills teaching, dictionary-integrated language learning and dictionary-assisted language learning. These types of use should form components of a dictionary pedagogy, which should ultimately result in autonomous dictionary use and the concurrent establishment of an individual dictionary culture with the learner. The lexicographer should take cognisance of all these aspects when a school dictionary is planned in order to intro-
\end{abstract}

Lexikos 20 (AFRILEX-reeks/series 20: 2010): 52-72 
duce the necessary lexicographical innovations. In closing, a few such innovations as well as suggestions for further research are proposed.

Keywords: CONTEXT, DICTIONARY PEDAGOGY, DICTIONARY SKILLS TEACHING, DICTIONARY USE, DICTIONARY-ASSISTED LANGUAGE LEARNING, DICTIONARY-INTEGRATED LANGUAGE LEARNING, LANGUAGE POLICY, LEARNER, LEARNER-CENTRED EDUCATION, LEARNING DICTIONARY, LEXICOGRAPHER, METALEXICOGRAPHY, PEDAGOGICAL DICTIONARY, REFERENCE DICTIONARY, SCHOOL DICTIONARY, SYSTEM, TARGET USER, TEACHER, USER-DRIVEN LEXICOGRAPHY

\section{Inleiding}

Die doel van hierdie artikel is om by te dra tot die metaleksikografiese gesprek oor skoolwoordeboeke. Die subklas skoolwoordeboeke vorm saam met die subklas aanleerderwoordeboeke die klas pedagogiese woordeboeke. Volgens Gouws en Tarp (2008: 66) bestaan daar verwarring wat die gebruik van die terme skoolwoordeboek en aanleerderwoordeboek betref. Terwyl skoolwoordeboeke afgestem is op skoolleerders wie se moedertaal die leksikografies behandelde taal is, fokus aanleerderwoordeboeke op die behoeftes van die teikengebruiker wat ' $n$ vreemde taal aanleer (Gouws en Prinsloo 2005: 51-52). ${ }^{1}$ Die veronderstelling is dus dat skoolwoordeboeke by verstek eentalige verklarende woordeboeke is, terwyl aanleerderwoordeboeke eentalig verklarende woordeboeke, tweetalige woordeboeke of tweetalig verklarende (die sg. "bilingualised") woordeboeke kan wees. Hierdie toegedigte kenmerke van die twee tipes pedagogiese woordeboeke behoort egter nie rigied toegepas te word nie: Die kenmerke wat 'n spesifieke tipe (pedagogiese) woordeboek vertoon, moet in die eerste plek die produk wees van die woordeboek se werklike doel, naamlik die vervulling van die teikengebruiker se inligtingsbehoeftes (Gouws 2006: 74). Die onderskeid van Prinsloo en Gouws (2005: 51-52) word in beginsel in hierdie artikel gehandhaaf, hoewel aangetoon sal word dat kontekstuele faktore 'n invloed op woordeboektipologie kan uitoefen.

Verreweg die meeste navorsing in die pedagogiese leksikografie tot op hede fokus op aanleerderwoordeboeke (Jackson 2002: 77, Bogaards 2003: 28, Kernerman 2007: 141-142), met skoolwoordeboeke wat byna glad nie figureer nie (vgl. egter vir Suid-Afrika: Lombard 1990, Louw 2004, Gouws 2006 en Hiles 2010). Een van die oorsake hiervan is waarskynlik, volgens Gouws en Prinsloo (2005: 51),

a false impression that they are easy to compile and merely require a cut and paste approach to extract them from bigger monolingual dictionaries.

So 'n benadering lei tot disfunksionele leksikografiese produkte wat in werklikheid groter taalvaardigheid van die teikengebruiker (die leerder) vereis as wat redelik in 'n gebruikersgedrewe leksikografie verwag kan word. Hartmann (2001: 75), wat dieselfde argument aanvoer, merk op dat die kreatiewe didak- 
tiek wat kenmerkend is van kinderwoordeboeke, in skoolwoordeboeke ontbreek. Hierdie kritiek was tot onlangs toe ook op die Afrikaanse leksikografie van toepassing, hoewel onlangse verwikkelinge belofte toon dat skoolwoordeboeke toenemend funksioneel beplan word, vgl. bv. Nuwe Woordeboek Sonder Grense (Gouws et al. 2004), HAT Afrikaanse skoolwoordeboek (Luther 2009 voortaan HAT Skoolwoordeboek) en die Longman Grondslagfasewoordeboek Afrikaans/Engels (Gouws et al. 2010). Ten spyte van hierdie verwikkelinge is daar steeds ruimte vir die uitbreiding van skoolwoordeboeke se potensiaal.

Hoewel die geïdentifiseerde funksies van ' $n$ bepaalde woordeboek 'n sentrale rol in die vasstelling van die datakategorieë en -verspreidingstruktuur van die woordeboek speel, poog hierdie artikel om 'n bydrae te maak tot die uitbreiding van skoolwoordeboeke se potensiaal deur kontekstuele faktore wat by die beplanning van skoolwoordeboeke ' $n$ rol kan speel binne die raamwerk van 'n kommunikatiewe woordeboekmodel (vgl. Beyer 2006) te verken. Binne hierdie model verteenwoordig onder meer die woordeboek (en dié se funksies, inhoud en strukture), die teikengebruiker, die gebruiksituasie en die konteks onderskeibare maar hoogs interafhanklike komponente. Met die term konteks word verwys na daardie versameling omgewingsveranderlikes wat normaalweg buite die invloedsfeer van die leksikograaf en die gebruiker in hulle onderskeie kapasiteite val, maar waarbinne én die leksikografiese proses én woordeboekgebruik plaasvind (Beyer 2006: 60). Binne 'n bepaalde konteks kan ongereguleerde subkontekste bestaan, bv. die veeltaligheid van 'n gemeenskap, sowel as gereguleerde subkontekste oftewel sisteme, bv. 'n nasionale grondwet. Suider-Afrika bestaan uit 'n versameling veeltalige samelewings, wat taalkontak en gevolglik taalverandering meebring. Behalwe vir die breër konteks van veeltaligheid vind taalonderrig ook binne bepaalde sisteme plaas. Die identifisering en verrekening van hierdie sisteme, wat as bepalers in die beplanning van gedrukte skoolwoordeboeke vir die sekondêre fase (graad 8 tot 12) geld, is die fokus van hierdie artikel.

Ter afsluiting word enkele voorstelle vir leksikografiese vernuwing in en navorsing oor skoolwoordeboeke na aanleiding van die geïdentifiseerde bepalers en bestaande funksies aan die hand gedoen.

\section{Makrosistemiese bepalers}

\section{$2.1 \quad$ Skoolkurrikula}

\subsubsection{Taalvakke}

Die makrosistemiese faktor wat die leksikograaf (in opdrag van die uitgewer) waarskynlik eerste by die beplanning van 'n skoolwoordeboek oorweeg, is die relevante (taal)vaksillabusse. Met betrekking tot die Suid-Afrikaanse konteks meld Van der Merwe (2009: 301) dat skoolsillabusse sedert 2002 spesifieke "uitkomstes" ten opsigte van woordeboekgebruik stel, byvoorbeeld dat leerders 
woorde in hulle alfabetiese plek sal kan vind en die spelling en betekenis van woorde sal kan nagaan.

Wat die Namibiese konteks betref, word daar in die sillabus van die junior primêre fase (graad 1 tot 4) geen eksplisiete melding van woordeboeke gemaak nie; daar word wel genoem dat leerders toegang tot ' $n$ wye verskeidenheid leesstof behoort te hê (Ministry of Basic Education, Sport and Culture 2004: 2), wat uiteraard woordeboeke kan insluit. Die sillabusgids vir eerstetaalonderwysers in dié fase (Ministry of Education 2005) bevat egter 'n aanbevole jaarplan vir elke graad waarin woordeboeke baie duidelik figureer. In Tabel 1 hieronder word die relevante basiese vaardighede weergegee:

Tabel 1: Basiese vaardighede met betrekking tot woordeboeke in die junior primêre fase (vertaal uit Ministry of Education 2005)

\begin{tabular}{|c|c|c|}
\hline Graad & Tema & Basiese vaardigheid \\
\hline 1 & 3: Kultuur in die familie & $\begin{array}{l}\text { Maak prentewoordeboeke (woorde } \\
\text { wat met dieselfde letter begin). }\end{array}$ \\
\hline 1 & $\begin{array}{l}\text { 11: Veiligheid in en om die } \\
\text { huis }\end{array}$ & $\begin{array}{l}\text { Begin eie woordeboeke maak (dik } \\
\text { potlode). }\end{array}$ \\
\hline 1 & 12: Voedsel & Gaan voort met woordeboeke. \\
\hline 1 & 13: Plaaslike plante & Gaan voort met woordeboeke. \\
\hline 2 & 4: Plaaslike kultuur & Vind woorde in 'n woordeboek. \\
\hline 2 & 13: Plaaslike voedsel & $\begin{array}{l}\text { Skryf nuwe woorde in 'n selfgemaakte } \\
\text { woordeboek. }\end{array}$ \\
\hline 2 & 19: Water & $\begin{array}{l}\text { Skryf alle nuwe woorde neer in die } \\
\text { woordeboek. }\end{array}$ \\
\hline 3 & 6: Openbare vakansiedae & $\begin{array}{l}\text { Gebruik 'n woordeboek om die } \\
\text { betekenis van woorde te vind. }\end{array}$ \\
\hline 3 & $\begin{array}{l}\text { 18: Identifikasie (van } \\
\text { plante) }\end{array}$ & $\begin{array}{l}\text { Beantwoord vrae skriftelik in gepaste } \\
\text { taal en korrigeer spelling met behulp } \\
\text { van 'n woordeboek of die onderwyser. }\end{array}$ \\
\hline 3 & $\begin{array}{l}\text { 19: Interafhanklikheid van } \\
\text { diere en hulle habitat }\end{array}$ & $\begin{array}{l}\text { Soek "diere"-woorde in 'n woordeboek } \\
\text { op en beskryf hulle. }\end{array}$ \\
\hline 4 & $\begin{array}{l}\text { 10: Hoe boere ons mense } \\
\text { voed }\end{array}$ & $\begin{array}{l}\text { Skryf 'n kort verhaal oor 'n plaas }( \pm 150 \\
\text { woorde). Kontroleer spelling in die } \\
\text { woordeboek. }\end{array}$ \\
\hline 4 & 23: Gesonde voeding & $\begin{array}{l}\text { Vind die betekenisse van nuwe } \\
\text { woorde in 'n woordeboek. }\end{array}$ \\
\hline 4 & $\begin{array}{l}\text { 29: Stowwe en hulle } \\
\text { eienskappe }\end{array}$ & $\begin{array}{l}\text { Oefen daagliks korrekte spelling deur } \\
\text { woordeboeke te gebruik. }\end{array}$ \\
\hline 4 & 33: Klank & $\begin{array}{l}\text { Lys nuwe woorde en vind hulle } \\
\text { betekenisse in konteks deur 'n } \\
\text { woordeboek te gebruik. }\end{array}$ \\
\hline
\end{tabular}


In die sillabus vir Afrikaans Eerste Taal in die senior primêre fase (graad 5 tot 7) word slegs verwag dat leerders hulle kennis van alfabetiese volgorde behoort te kan toepas "by die gebruik van verskillende soorte media, bv. woordeboeke, indekse, ens." (Ministry of Basic Education and Culture 2000: 17). Die sillabus vir Afrikaans Eerste Taal in die junior sekondêre fase (graad 8 tot 10) gee meer uitgebreide aandag aan woordeboeke met die formulering van die volgende basiese vaardighede onder verskillende doelstellings (Ministry of Education 2007: 9, 16). Leerders behoort naamlik in staat gestel te word om

- $\quad$ kort tekste van verskillende aard (storie, drama, koerantberig, woordeboekinskrywing, afkondiging, ens.) vlot en akkuraat voor te lees [slegs graad 8 - HLB],

- betekenis, spelling en idiomatiese gebruik van woorde in woordeboeke na te slaan,

- woordeboeke en ander beskikbare naslaanwerke te gebruik om spelling, betekenis en addisionele inligting na te slaan, soos afkortings, idiomatiese uitdrukkings, woordsoort, ens., en

- elektroniese bronne (waar beskikbaar) te gebruik vir naslaandoeleindes.

In die sillabusse vir Afrikaans Eerste Taal in die senior sekondêre fase (graad 11 en 12) word vir beide die gewone en hoër vlakke bloot van leerders verwag om "woordeboeke vir verskillende doeleindes" te kan raadpleeg (Ministry of Education 2006: 8, Ministry of Education 2006a: 8).

Dit is belangrik vir die leksikograaf om te besef dat kurrikuleerders met betrekking tot woordeboeke slegs sodanige gebruiksvaardighede kan voorskryf as wat die beskikbare (skool)woordeboeke inligting bied. Indien die beskikbare woordeboeke byvoorbeeld nie aanduidings van antonieme bevat nie, kan sillabusse nie vereis dat leerders in staat behoort te wees om antonieme in woordeboeke te vind nie. Met betrekking tot skoolwoordeboeke kan daar dus 'n dooie kringloop ontstaan: Leksikograwe en uitgewers bepaal die datakategorieë wat in hulle woordeboeke aangebied sal word op grond van wat sillabusse ten opsigte van woordeboekgebruik voorskryf, en kurrikuleerders bepaal wat sillabusse ten opsigte van woordeboekgebruik sal voorskryf op grond van watter inligting in woordeboeke aangebied word. Die onus lê op die leksikografie om (a) skoolwoordeboeke te produseer wat nie bloot aan die minimum sillabusvereistes voldoen nie, maar wat binne die beperkinge van die beskikbare media ook innoverend is, en (b) aan belanghebbendes in die onderwyssektor leksikografiese voorligting te bied.

\subsubsection{Basiese Inligtingkunde}

Verwysings na woordeboekgebruik in Namibiese skoolkurrikula is nie tot die taalvakke beperk nie. In die sillabus vir die vak Basiese Inligtingkunde wat in 
die senior primêre fase vir alle leerders aangebied word, kom woordeboeke as tema in graad 5 voor met die leerdoelstelling dat leerders moet leer hoe om ' $n$ woordeboek te gebruik (Ministry of Education 2007: 11). Die basiese vaardighede is (ongelukkig) beperk tot leerders se vermoë om inligtings- en kommunikasietegnologieterme in ' $n$ woordeboek te vind en te gebruik. Woordeboeke figureer nie in die leerinhoude vir graad 6 en 7 nie.

Wanneer die Namibiese sillabusse in chronologiese volgorde beskou word, wil dit voorkom asof daar 'n toenemende bewustheid onder besluitnemers oor die gebruik van woordeboeke en woordeboekonderrig aan die ontwikkel is. Sistematiese progressie in woordeboekvaardigheid ontbreek egter binne en tussen skoolfases. Ten opsigte hiervan kan die leksikografie kurrikuleerders bystaan in die ontwikkeling van 'n deurlopende woordeboekpedagogie.

Die oorweging van kontekstueel-sistemiese faktore buiten kurrikula kan ook waarde tot skoolwoordeboeke toevoeg. Enkele sodanige faktore word vervolgens kortliks uiteengesit.

\subsection{Die nasionale taalbeleid vir skole}

In die veeltalige konteks van Namibië geld die grondwetlike bepaling dat Engels die (enigste) amptelike taal is en dat daarnaas dertien nasionale tale erken word. Volgens die nasionale taalbeleid vir skole (Ministry of Education and Culture 1993) word moedertaalonderrig tot in graad 3 toegelaat, met Engels wat as onderrigmedium vanaf graad 4 ingefaseer word en vanaf graad 8 as die enigste onderrigmedium in Namibiese staatskole geld. Die nasionale tale wat as skoolvakke aangebied word, word uiteraard deur die medium van die betrokke taal onderrig. Die implikasie is dat byvoorbeeld moedertaalsprekers van Afrikaans na graad 3 vir maksimaal 15,4\% van hulle klastyd aan Afrikaans blootgestel word (vgl. Ministry of Basic Education, Sport and Culture 1996: 21). In alle ander vakke vind alle kommunikasie deur die medium van Engels plaas, wat groot druk op Afrikaanstalige leerders se moedertaalleksikon- en taalvaardigheidsontwikkeling plaas, aangesien hulle Engelse leksika in sekere gevalle vinniger uitbrei as dié van hulle moedertaal. In sommige gevalle sal leerders met Afrikaans as moedertaal byvoorbeeld 'n saak of begrip beter in Engels kan benoem as in Afrikaans. Indien van hierdie leerders dan verwag word om hulle deurlopend in Standaardafrikaans uit te druk, soos wat in die Afrikaansklas die geval is, kan dit gebeur dat die leerders 'n tweetalige woordeboek soos die Oxford Afrikaans-Engels/English-Afrikaans Skoolwoordeboek/ School Dictionary (Louw 2007) raadpleeg om ' $n$ bepaalde moedertaalekwivalent van 'n Engelse leksikale item (terug) te vind. In hierdie geval word dié tweetalige woordeboek dan tipologies gesproke nie as aanleerderwoordeboek gebruik nie, maar tereg as skoolwoordeboek - met die moedertaal as doeltaal. Binne die huidige Namibiese konteks is dit dus nie vergesog dat die subklas skoolwoordeboeke tipologies gesproke nié sonder meer deur eentalig verklarende 
woordeboeke verteenwoordig word nie. Die veeltalige konteks en die geldende nasionale taalbeleid vir skole in Namibië het dus duidelik 'n invloed op die benutting van (skool)woordeboeke, wat spesifieke leksikografies relevante behoeftes weerspieël waarvolgens die relevante woordeboektipologieë bepaal behoort te word.

\subsection{Die beleid van leerdergerigte onderwys}

'n Makrosistemiese faktor wat 'n gulde geleentheid vir die gebruik van skoolwoordeboeke bied, maar wat ook by die ontwerp van skoolwoordeboeke in ag geneem behoort te word, is die beleid van leerdergerigte onderwys, wat voortspruit uit sosiale konstruktivisme (Combrink et al. 1997: 6). Volgens die Pilot Curriculum Guide for Formal Basic Education (Ministry of Basic Education, Sport and Culture 1996: 25) behoort leerdergerigte onderwys die volgende eienskappe te vertoon:

- the starting point at each stage of a learning process is each learner's existing knowledge, skills, interests and understanding, derived from previous experience in and out of school;

- the natural curiosity and eagerness of all young people to learn to investigate and make sense of a widening world must be catered for by a variety of challenging and meaningful tasks;

- the learner's perspective must be appreciated and taken into consideration in the work of the school;

- learners should be empowered to think and take responsibility not only for their own, but for each other's learning and development; and

- they should be involved as partners in, rather than receivers of, education.

In die besprekingsdokument Learner-Centred Education in the Namibian Context: A Conceptual Framework (NIED 2003: 25-27) word die implikasies van leerdergerigte onderwys op leer- en ondersteuningsmateriaal uitgelig. Die volgende punte wat op skoolwoordeboeke as leer- en ondersteuningsmateriaal van toepassing kan wees, is geëkstraheer:

- Die herwaardering van die rol van leer- en ondersteuningsmateriaal in die bereiking van substansiële leer: Materiaal moet die leerproses ondersteun in plaas van domineer.

- Leerders se vorige ervaring en leer moet in ag geneem word en geleenthede vir verkenning en probleemoplossing bied.

- Materiaal behoort ' $n$ raamwerk vir die fasilitering van leer te skep waarin vraagstelling, vergelyking en verkenning deurgaans op verworwe kennis bou. 
Die innoverende gebruik van skoolwoordeboeke in die taalklas kan effektief bydra tot die toepassing van leerdergerigte (taal)onderrig, mits skoolwoordeboeke voldoende didaktiese elemente bevat en taalonderwysers voldoende in hierdie verband opgelei is. Dít vra om leksikografiese vernuwing en gerigte woordeboekpedagogieë.

\subsection{Kruiskurrikulêre onderrig}

Binne die beleid van leerdergerigte onderwys figureer ' $n$ belangrike benadering, naamlik dié van kruiskurrikulêre onderrig. Hierdie benadering word soos volg in ' $n$ beleidsdokument toegelig (Ministry of Basic Education and Culture 1998: 8):

Cross-curricular teaching can be formally organised around topics and themes. A common topic in two or more subjects is planned so that it will be taught simultaneously, e.g. population statistics. The Mathematics teacher might go into the technical problems of population statistics and how that could be presented, the teacher of Geography will take up the significance of population statistics for understanding population growth, demographic aspects and the relation of population and land resources. The English teacher may present literary extracts illustrating the human dilemmas which result from overpopulation.

Die opdrag aan die Namibiese Afrikaansonderwyser binne hierdie benadering is duidelik: Ontwikkel leerders se taalvaardigheid in Afrikaans parallel met die betrokke sentrale tema wat eksklusief deur die medium van Engels in die ander vakke behandel word. Hierdie opdrag sluit vanselfsprekend die parallelle uitbouing van leerders se Afrikaanse leksika in. Die gebruik van 'n tweetalige (skool)woordeboek om moedertaalekwivalente vir Engelse terme wat in al die ander vakke gebruik word te vind, dit wil sê die gebruik van sodanige woordeboek as skoolwoordeboek in plaas van aanleerderwoordeboek, is gevolglik binne ' $n$ leerdergerigte situasie nie 'n onredelike veronderstelling nie. Trouens, dit kan selfs 'n staande opdrag in die Afrikaansklas wees: Aan die begin van elke Afrikaansperiode word 'n paar minute afgestaan aan die vind van Afrikaanse vertaalekwivalente vir Engelse terme wat in ander vakke gebruik is deur hulle in 'n tweetalige skoolwoordeboek na te slaan. So 'n klasbeleid kan ook tot die vestiging van 'n taalbewustheid onder leerders bydra.

Die benadering van kruiskurrikulêre onderrig binne die Namibiese konteks en die leksikografies relevante inligtingsbehoeftes wat daaruit voortspruit, kan dus ook 'n hersiening van bestaande woordeboektipologieë (m.b.t. pedagogiese woordeboeke) motiveer.

\subsection{Perspektief op makrosistemiese bepalers}

In die voorafgaande bespreking is enkele makrosistemiese faktore uitgelig wat die beplanning en gebruik van skoolwoordeboeke kan — en behóórt te - beïn- 
vloed. Daar is nie na ' $n$ uitputtende identifikasie en beskrywing van die tersaaklike faktore gestreef nie. Die sentrale argument is wel dat skoolwoordeboeke wat slegs op sillabusvereistes met betrekking tot woordeboekgebruik gegrond is nie die potensiaal van die pedagogiese leksikografie ten opsigte van hierdie woordeboektipe sal verwesenlik nie. Presies hoe die oorweging van die bespreekte faktore tot beter skoolwoordeboeke aanleiding kan gee, sal later in die artikel aan die hand van enkele voorstelle vir leksikografiese vernuwing toegelig word.

\section{Die teikengebruiker en mikrosistemiese bepalers}

In die moderne leksikografie staan die gebruikersperspektief voorop: Die inligtingsbehoeftes en naslaanvaardighede van 'n goed gedefinieerde teikengebruiker is kritiese veranderlikes in die beplanning van 'n woordeboek (vgl. o.m. Gouws en Prinsloo 2005: 39). Op die vraag wie die teikengebruiker van 'n skoolwoordeboek is, is die vanselfsprekende antwoord "die leerder". 'n Leerder ondervind binne (of buite) die onderrigleersituasie 'n behoefte aan sekere inligting wat deur die kommunikatiewe en kognitiewe funksies van die gepaste woordeboek bevredig kan word, indien die leerder se naslaanvaardighede hom/haar toegang tot die relevante data bied (vgl. Tarp 2008). Die leksikograaf wat ' $n$ akkurate profiel van die leerder kan saamstel, kan 'n funksionele skoolwoordeboek tot stand bring.

Volgens die Dictionary of Lexicography (Hartmann en James 1998: 107) is ' $n$ pedagogiese woordeboek "a reference work specifically designed for the practical didactic needs of teachers and learners of a language". Hierdie definisie maak die belangrike punt dat ' $n$ skoolwoordeboek ook die praktiese didaktiese behoeftes van die taalonderwyser behoort aan te spreek: Die taalonderwyser is medeteikengebruiker en mag nie in die beplanning van 'n skoolwoordeboek oorgesien word nie. Hiervoor moet die leksikograaf inligting oor die onderrigleersituasie as mikrosistemiese konteksfaktor inwin.

\subsection{Die onderrigleersituasie}

In waarskynlik die meeste gevalle word woordeboekgebruik in die onderrigleersituasie op die een of ander manier deur die onderwyser gestimuleer. Hierdie stimulering kan in die volgende gevalle plaasvind: (a) Die onderwyser bied onderrig in woordeboekgebruik aan, wat in die ideale situasie die praktiese toepassing van woordeboekgebruik deur die leerders insluit. Vir hierdie doel voorsien baie uitgewers ook woordeboekwerkboeke en -gidse, bv. HAT Aktiwiteite en speletjies by die Afrikaanse skoolwoordeboek en Afrikaanse sakwoordeboek (Luther 2010). (b) In die uitvoering van 'n taak (bv. die skryf van 'n opstel in die klas) ondervind die leerder 'n behoefte aan bepaalde leksikografies relevante inligting. Die leerder nader die onderwyser of 'n medeleerder om hulp, 
wat óf die nodige inligting sonder meer aan die leerder verskaf ('n nie-ideale, nie-leerdergerigte situasie), óf die leerder na die woordeboek verwys (die ideale, leerdergerigte situasie: stimulering van woordeboekgebruik). Indien die leerder effektiewe woordeboekonderrig ondergaan het en 'n naslaankultuur word in 'n leerdergerigte onderrigleersituasie aangemoedig, sal hy/sy die woordeboek direk nader. Gouws (2009: 83) verwys na hierdie tipe woordeboekgebruik as geïsoleerde woordeboekgebruik. (c) Die taalonderwyser integreer die woordeboek op voorafbeplande wyse in die onderrigleersituasie deur leerders woordeboeke te laat gebruik om by te dra tot die bereiking van die een of ander lesdoelwit. Geval (a) staan bekend as woordeboekonderrig (WO - as komponent van 'n woordeboekpedagogie) en is gewoonlik afgestem op die verwerwing van daardie basiese vaardighede in die sillabus wat woordeboekgebruik spesifiseer, soos in 2.1 aangetoon. Geval (b) kan, na analogie van die term rekenaargesteunde taalonderrig, beskryf word as woordeboekondersteunde taalonderrig (WST). Geval (c) kan beskryf word as woordeboekgeïntegreerde taalonderrig (WIT), wat Gouws (2009: 83) ook geïntegreerde woordeboekgebruik noem. Die doelwit van elkeen van hierdie gevalle van woordeboekgebruik kan soos volg uiteengesit word:

WO: die verwerwing van 'n bepaalde woordeboekvaardigheid,

WST: die inwinning van die benodigde inligting om ' $n$ taak te voltooi, en

WIT: die bereiking van 'n lesdoelwit deur leerdergerigte onderrigleeraktiwiteite.

'n Verdere belangrike verskil tussen WST enersyds en WO en WIT andersyds is dat WST in die ideale situasie deur die leerder geïnisieer word, terwyl die inisieerder by WO en WIT die taalonderwyser is. Die kollektiewe algemene doelstelling van al drie gevalle is die bereiking van ' $n$ situasie waarin die leerder ' $n$ woordeboekgeletterde gebruiker is wat outonome woordeboekgebruik (OWG) toepas en sodoende ' $\mathrm{n}$ individuele woordeboekkultuur (IWK) besit. Ongelukkig is dit in baie onderrigleersituasies die veronderstelling - selfs die verwagting - dat WST alleen tot OWG sal lei. In die uitsluitlik WST-situasie probeer woordeboekongeletterde leerders om woordeboeke te gebruik, wat aanleiding gee tot onsuksesvolle naslaanprosedures en die gepaardgaande ongunstige houding jeens woordeboekgebruik (vgl. Carstens 1995: 107-109). 'n Skoolwoordeboekpedagogie behoort al hierdie gevalle van woordeboekgebruik te inkorporeer, en hoewel die tipes afwisselend kan voorkom, is die volgende oorkoepelende toepassingsorde pedagogies gewens, met die mikrokonteks van die onderrigleersituasie wat deur die stippellyn afgebaken word:

$$
\text { WOHIT } \rightarrow \text { WST } \rightarrow \text { OWG }
$$

Dit is belangrik om in gedagte te hou dat die algemene doelstelling van ' $\mathrm{n}$ woordeboekpedagogie nie bloot OWG is nie, maar dat dit progressief tot ' $n$ 
IWK behoort te lei. Selfs die vestiging van 'n IWK behoort nie die hoofdoel te wees nie, want, soos Béjoint (1989: 209) beklemtoon,

dictionary use is not an end in itself; it is only a means that can be used to improve one's mastery of the language.

Dit word dus duidelik dat WO, soos in skoolsillabusse voorgeskryf, maar die eerste (noodsaaklike) stap tot OWG en uiteindelik 'n IWK is. Die komplementerende benadering van WIT dra daartoe by dat woordeboeke hulle volle potensiaal as instrumente in taalonderrig oftewel taalverwerwing kan verwesenlik.

\subsection{Woordeboekgeïntegreerde taalonderrig (WIT)}

Om WIT verder van WST te onderskei, kan 'n kommunikasieketting ten opsigte van die leer(onderrig)aktiwitweit in elke benadering beskou word: ${ }^{2}$

$$
\begin{aligned}
& \text { WST: } \ldots \rightarrow \text { leerder }(\rightarrow \text { taalonderwyser } \rightarrow \text { leerder }) \rightarrow \text { WOORDEBOEK } \rightarrow \ldots \\
& \text { WIT }: \ldots \rightarrow \text { taalonderwyser } \rightarrow \text { leerder } \rightarrow \text { WOORDEBOEK } \rightarrow \ldots
\end{aligned}
$$

Soos reeds aangetoon, wys hierdie uiteensetting ook op die inisieerder van woordeboekgebruik in elke geval. In die WST-situasie ondervind die leerder onafhanklik ' $n$ behoefte aan leksikografies relevante inligting en inisieer (uiteindelik) woordeboekgebruik. Die inligting wat die leerder inwin, word benut om 'n taak te voltooi. In die WIT-situasie inisieer die taalonderwyser woordeboekgebruik deur by die leerders ' $n$ behoefte aan leksikografies relevante inligting te skep en die geleentheid te bied om 'n woordeboek gerig te gebruik. Ter illustrasie volg ' $n$ eenvoudige voorbeeld van WIT:

Die taalonderwyser wil die volgende basiese vaardigheid in die sillabus vir Afrikaans Eerste Taal in graad 10 op 'n leerdergerigte manier vestig of konsolideer (Ministry of Education 2007: 13): Leerders behoort in staat te wees om

- hoofletters en leestekens korrek en effektief te gebruik (kappie, koppelteken, deelteken, afkappingsteken en aksentteken).

Die fokus is op die gebruik van die afkappingsteken by meervouds- en verkleinwoordvorme. Die onderwyser identifiseer die volgende relevante spelreëls volgens die leerstof of, soos in hierdie geval, die Afrikaanse woordelys en spelreëls (Taalkommissie 2009: 7-11):

Reël 2.1: Die afkappingsteken word gebruik by meervoudsvorme op -s en die verkleiningsvorme van naamwoorde wat op die vokaalletters $\mathbf{i}$, o en $\mathbf{u}$ eindig.

Reël 2.7: Die afkappingsteken word gebruik by meervoudsvorme op -s en verkleiningsvorme van naamwoorde wat eindig op 'n lank uitgespreekte a ('n [a:]klank wat met slegs een a gespel word) wat die hoofklem dra. 
Reël 2.8: Die afkappingsteken word gebruik by die meervoudsvorme op -e en die verkleiningsvorme van selfstandige naamwoorde wat eindig op ' $n$ e wat nie uitgespreek word nie.

Die volgende onderrigleeraktiwiteit, geskoei op die beginsels van leerdergerigte onderwys, word voorberei: Die leerders (wat reeds WO ontvang het) word gevra om 'n gegewe lys woorde in die woordeboek na te slaan en ten opsigte van elke woord (a) die meervouds- en verkleinwoordvorm na te gaan en neer te skryf, en (b) die vokaal of diftong wat volgens die woordeboek die hoofklem in elke woord dra, te onderstreep (soos in die HAT Skoolwoordeboek). Die lys woorde bestaan uit items wat aan die reëls hierbo onderhewig is sowel as items waarop dié reëls nie van toepassing is nie. Hierdie aktiwiteit verteenwoordig die moment van woordeboekintegrasie. Nadat die leerders die woordeboek gebruik het, word hulle opdrag gegee om die woorde volgens meervouds- en verkleinwoordvorming te klassifiseer en om in die klas woorde waarby die afkappingsteken voorkom uitspraakpatrone te soek. Die onderwyser lei die leerders dan gaandeweg om die tersaaklike reëls van die taalkundige gegewe af te lei in plaas daarvan om bloot die reëls weer te gee, met ander woorde ' $n$ induktiewe in plaas van 'n deduktiewe werkswyse (vgl. Meij et al. 1985: 6) word gevolg waarin WIT bydra tot leerdergerigte taalonderrig. Ter ondersteuning van hierdie benadering het Meij et al. (1985: 26-27) met betrekking tot die onderrig van spelling bevind

dat leerlinge wat al die reëls loop leer het, skaars beter spellers is as die wat maar net goeie lesers is. Dus, ten spyte van die feit dat ons leerlinge spelreëls van jongs af leer, is die waarde daarvan nie baie duidelik nie.

$\mathrm{Al}$ meer en meer lyk dit of die interne reël wat elke gebruiker vir homself aflei, van meer waarde kan wees.

Hierdie voorbeeld van WIT verteenwoordig ook 'n geval waar die woordeboek as leerwoordeboek in plaas van naslaanwoordeboek (vgl. Hausmann 1977: 144) gebruik word, want die woordeboekgebruik behels nie 'n enkele naslaanprosedure wat ten doel het om spesifieke inligting met betrekking tot een bewerkingseenheid (bv. 'n lemma) te onttrek nie, maar 'n reeks naslaanprosedures waardeur gelyksoortige inligting uit verskillende woordeboekartikels onttrek en daarna vir die doel van studie vergelyk word. In hierdie geval het die woordeboek naamlik 'n kognitiewe eerder as 'n kommunikatiewe funksie vervul (vgl. Tarp 2008: 46). Dit is hier belangrik om daarop te wys dat WIT nie die uitsluitlike gebruik van woordeboeke as leerwoordeboeke veronderstel nie. WIT sluit geensins die gebruik van woordeboeke as naslaanwoordeboeke uit nie; trouens, in die ideale situasie sou die leerder tydens WST en uiteindelik OWG ook die woordeboek as leerwoordeboek kon benut. 'n Leerdergerigte skoolwoordeboek wat wil bydra tot leerdergerigte onderwys, behoort as beide naslaanwoordeboek en leerwoordeboek gebruik te kan word, hoewel die ontwerp van 'n skoolwoordeboek nie leerwoordeboekfunksionaliteit ten koste van naslaanwoordeboekfunksionaliteit mag bevorder nie. Vanuit 'n leksikografiese 
oogpunt kan leerwoordeboekfunksionaliteit as toegevoegde waarde beskou word. Die onderskeidende kenmerk van 'n woordeboek lê juis in sy naslaanfunksionaliteit (vgl. Tarp 2008: 46), hoewel hierdie kenmerk op sý beurt weer nie die moontlikheid van 'n uitgebreide funksionaliteit behoort uit te sluit nie. Dit is onder meer op hierdie punt waar die leksikograaf met vernuwing kan reageer.

Die breë konsep van WIT is nie nuut nie; trouens, die nasionale vakbeleid vir Engels Eerste Taal bevat die volgende stelling ten opsigte van woordeboekgebruik (Ministry of Education 2008: 4):

Teachers should plan lessons in such a way that learners are expected to use dictionaries.

'n Soortgelyke stelling kom egter nie in die nasionale vakbeleid vir Afrikaans Eerste Taal voor nie.

Baie taalonderwysers is nie bevoeg om WIT toe te pas nie, hoofsaaklik omdat hulle self nooit aan 'n woordeboekpedagogie blootgestel is nie. Opleiding in woordeboekgebruik moet in die eerste plek by onderwysers begin (Béjoint 1989: 208), en dié aspek moet in enige deeglike woordeboekpedagogie vir skole neerslag vind.

\section{Voorstelle vir leksikografiese vernuwing en navorsing}

Hierdie afdeling bied enkele voorstelle vir vernuwing in en navorsing oor skoolwoordeboeke, veral met die oog op leerdergerigte taalonderrig. Die fokus val op 'n aantal bestaande en potensiële datakategorieë in die sentrale lys, hoewel ' $n$ uitgebreide dataverspreidingstruktuur (d.w.s. 'n raamstruktuur) vir 'n skoolwoordeboek veronderstel word (vgl. Gouws en Prinsloo 2005: 58). Buitetekste word weens beperkte ruimte in hierdie artikel buite rekening gelaat. Voorbeelde van woordeboekartikels kom uit die HAT Skoolwoordeboek en hipotetiese woordeboekartikels is op artikels uit hierdie woordeboek gebaseer.

\subsection{Die makrostruktuur}

Binne die Namibiese konteks is die aangewese medium vir skoolwoordeboeke tans steeds die gedrukte medium. Beide die medium en die tipologiese klas waartoe die skoolwoordeboek behoort plaas sekere beperkinge op die omvang daarvan. 'n Skoolwoordeboek kan nie dieselfde omvang as 'n omvattende woordeboek hê nie, en daarom moet die leksikograaf 'n beperkte lemmalys saamstel. In die HAT Skoolwoordeboek word geen melding gemaak van die kriteria wat vir die samestelling van die makrostruktuur aangelê is nie. Op die flapteks word bloot genoem dat die woordeboek "meer as 30000 woorde en hul verbuigings, duisende vaste uitdrukkings en idiome, inligting oor die herkoms van woorde en afkortings" bevat. In die Voorwoord van die Oxford Secon- 
dary School Dictionary (Oxford University Press Southern Africa 2006: iv) word gemeld dat dié woordeboek, behalwe woorde uit Suid-Afrikaanse Engels, "the special vocabulary of curriculum subjects" bevat. Die veronderstelling is dat die uitgewers skoolsillabusse en leerstof raadpleeg en gespesialiseerde korpora en databasisse gebruik by die seleksie van lemmata. Indien korpora van leerders se skryfwerk beskikbaar is, sou 'n proskriptiewe benadering (vgl. Tarp en Gouws 2008: 239-240) oorweeg kon word. Woorde wat leerders geneig is om verkeerd te spel, kan byvoorbeeld geïdentifiseer word, en in hulle verkeerde spelling opgeneem en van die nodige proskriptiewe kommentaar voorsien word, soos in die volgende hipotetiese artikel:

parralel Verkeerde spelling van parallel

Wat betref die toepassing van gebruiksfrekwensie met behulp van korpora om 'n makrostruktuur saam te stel, het De Schryver et al. (2006) bevind dat die mees frekwente woorde nie noodwendig dié woorde is wat woordeboekgebruikers opsoek nie - dit kan juis vir inligting oor die minder frekwente en derhalwe minder bekende woorde wees waarvoor ' $n$ woordeboek geraadpleeg word. Afgesien van watter benadering tot die identifisering van lemmata gevolg word, is die uiteindelike vrae vanuit 'n funksionele oogpunt: Watter woorde slaan leerders vir watter doel na? Watter woorde wil onderwysers hê moet leerders vir watter doel naslaan? Gebruik(er)snavorsing om hierdie twee vrae te beantwoord, is dringend nodig. Verder moet die leksikograaf sy/haar beplande woordeboek se potensiële bydrae tot leerdergerigte onderwys in gedagte hou. Dit veronderstel dat die leksikograaf ook van taalonderrigmetodiek kennis moet neem.

\subsection{Die mikrostruktuur}

\subsubsection{Woordsoorte}

Die aanduiding van woordsoorte behoort uiteraard in ooreenstemming met die betrokke kurrikula te wees. Die hantering van die lemma haar in die HAT Skoolwoordeboek sien soos volg daaruit:

haar ${ }^{1} v n w$. (woord wat verwys na 'n vroulike persoon as dit nie die onderwerp van 'n sin is nie; iets wat 'n vrou s'n is, behoort aan haar, is hare): Ek sien haar al van ver af aankom. $\circ$ Sy leen nooit haar boeke uit nie. $\circ$ Gee die teddiebeer vir jou sussie; dis hare.

Dat daar geen eksplisiete onderskeid tussen die persoonlike en besitlike voornaamwoord haar getref word nie, maak die artikel onbruikbaar vir WIT (én WST) wanneer dit by die onderrig van woordsoorte kom. In 'n aangepaste bewerking behoort die voorbeeldsinne ook op eksplisiete wyse deur 'n gepaste 
leksikografiese prosedure aan die betrokke subwoordsoort gekoppel te word. Vergelyk die volgende voorgestelde herbewerking:

haar ${ }^{1}$ vnw. - pers. vnw. wat verwys na ' $n$ vr. pers. en wat nie die onderwerp van ' $n$ sin is nie: Ek sien haar al van ver af aankom. $\rightarrow \mathbf{s y}^{3} \mathbf{a}$ besitl. vnw. wat besit deur ' $n$ vr. pers. aandui: Sy leen nooit haar boeke uit nie.

In die bostaande artikel gaan die nie-tipografiese struktuurmerker a die subwoordsoort vooraf om 'n afsonderlike soeksone af te baken waarbinne ook die relevante voorbeelde gegroepeer word. 'n Subwoordsoortaanduider hoef nie slegs ' $n$ enkele afkorting te wees nie: In hierdie geval is die volledige subwoordsoortaanduider vir die persoonlike voornaamwoord pers. vnw. wat verwys na 'n vr. pers. en wat nie die onderwerp van 'n sin is nie. ('n Verwysing na die onderwerpsvorm van die voornaamwoord is ook ingevoeg.) Effektiewe WO en 'n funksionele gebruikersgids behoort te verseker dat die afkortings wat gebruik word, nie vir die hoërskoolleerder 'n probleem is nie. (Trouens, die gebruik van afkortings in woordeboekartikels bied die geleentheid vir WIT wanneer afkortings behandel word.)

\subsubsection{Intensiewe vorme en vergelykings}

In die HAT Skoolwoordeboek word intensiewe vorme (bv. brandarm) en vergelykings (bv. so arm soos ' $n$ kerkmuis) in onderskeidelik 'n voorteks getiteld "Intensiewe vorme" en 'n agterteks getiteld "Vergelykings" in alfabetiese volgorde volgens die betrokke adjektief gelys. So kom intensiewe vorme vir 111 adjektiewe in die betrokke voorteks en 96 vergelykings in die betrokke agterteks voor. Hoewel die tersaaklike datakategorieë in enkele maklik toeganklike tekste saamgegroepeer is, bevorder dié tipe aanbod nie leerdergerigte taalonderrig of WIT nie. Vanuit 'n leerdergerigte oogpunt sal hierdie datakategorieë meer doeltreffend in die mikrostruktuur aangebied word, ${ }^{3}$ soos in die volgende hipotetiese artikel van die lemma arm²:

$\operatorname{arm}^{2} b . n w ., b w$. [ of $\sim$ e; armer, die armste] 1 arm wees baie min geld en nie veel besittings hê nie. $\diamond$ INTENS. VORM: brandarm $\diamond$ VERG.: kerkmuis. 2 arm aan iets wees nie veel daarvan hê/besit nie: ' $n$ skaam meisie, arm aan woorde $\circ$ grond wat arm aan stikstof is. 3 ongelukkig; ellendig: Die arme mense het sopnat gereën.

Indien die taalonderwyser om die een of ander rede ' $n$ lys van intensiewe vorme of vergelykings wil saamstel, kan dit met behulp van die woordeboek 'n opdrag aan die leerders wees - wat óók 'n geval van WIT verteenwoordig. Leerders kan verder gevra word om (hulle eie kreatiwiteit te gebruik om) vorendag te kom met intensiewe vorme en vergelykings van adjektiewe waarvoor daar nié sodanige data in die woordeboek verstrek word nie. WIT kan dus bou nie net op wat die woordeboek bied nie, maar ook op wat die woordeboek nié bied nie. 


\subsubsection{Metafore}

Die aanduiding van metafore is ' $n$ potensiële datakategorie vir ' $n$ skoolwoordeboek. Vergelyk die volgende hipotetiese artikel:

mor.sig b.nw., bw. [ e] vuil; smerig: 'n morsige vent wat nooit bad nie • Hoe kan 'n mens in so 'n morsige huis lewe? METAF.: vark (neerh.)

Weer eens sal WO en 'n funksionele gebruikersgids die leerder met die interpretasie van die inskrywings "METAF.: vark (neerh.)" help: "Om iemand (op neerhalende wyse) as morsig te beskryf, kan ook gesê word dat daardie persoon 'n vark is."

\subsubsection{Idiome}

Leerders wat idiome (en metafore) gepas in hulle skryfwerk gebruik, toon meer gevorderde taalbeheersing as diegene wat nie dié vaardigheid demonstreer nie. Gevolglik presteer sodanige leerders ook beter. Die leer van lyste idiome vir eksamen- of opstelskryfdoeleindes vanweë die moontlikheid dat hulle êrens nuttig te pas kan kom, getuig van 'n soortgelyke benadering as die uitwendige leer van spelreëls (vgl. 4.1). Sodanige benadering word bevorder deurdat woordeboeke tradisioneel met betrekking tot idiome slegs vir die funksie van teksresepsie voorsiening maak deur hulle opname in artikels van lemmata wat een van hulle komponente verteenwoordig. Die betrokke datakategorie is dus slegs via een soekroete toeganklik. Vergelyk die volgende voorbeeld:

on'kant b.nw. onkant wees (rugby, hokkie, sokker) in 'n posisie wees waarin jy nie mag speel nie. iem. onkant betrap iemand in 'n situasie verras sodat hy/sy nie dadelik weet hoe om te reageer nie: Sy huweliksaansoek het haar onkant betrap.

Oor die leksikale en lemmastatus van idiome word nie uitgewei nie - vgl. hiervoor Gouws (1989: 98-101). Die woordeboekgeletterde leerder wat die idioom iemand onkant betrap tydens teksresepsie teëkom, kan dit aan die hand van die bostaande artikel interpreteer. Dieselfde leerder kan dit egter nie met behulp van die woordeboek as ' $n$ gepaste idioom vind om ' $n$ vorm van verrassing in 'n teksproduksiesituasie uit te druk nie. Hierdie leemte kan minstens gedeeltelik oorkom word deur 'n nuwe datakategorie in die artikel van die semanties verbandhoudende of sinonieme lemma in te voer, soos in die volgende hipotetiese artikel:

ver.ras $w w$. [het $~]$ iem. verras iets doen wat iemand nie verwag het nie: Die man het sy vrou met ' $n$ bos blomme verras. $\circ$ Die vyand het hulle verras deur hulle van agter aan te val. •Die Springbokke se oorwinning het baie mense verras. DIDM.: onkant 
Die datakategorie wat deur die inskrywingsreeks " IDM.: onkant" verteenwoordig word, verwys die leerder wat verras opsoek, na die artikel van die lemma onkant vir 'n idioom wat hy/sy sou kon gebruik om die begrip verras uit te druk sodat dié data dus politoeganklik en funksioneel gelykwaardig aan dié van leksikale lemmata gemaak word. Die behandeling van die idioom gee aan die leerder ' $n$ aanduiding van die gepastheid daarvan vir die relevante diskoerskonteks. Alle idiome kan egter nie op hierdie manier politoeganklik gemaak word nie; daarom is verdere studie en voorstelle in hierdie verband nodig.

\subsubsection{Afkortings}

Indien kurrikula van leerders verwag om afkortings ook te kan gebruik en nie net te interpreteer nie, geld dieselfde argument as by idiome hierbo. Die afkortings van afkortbare lemmata behoort in die betrokke woordeboekartikels opgeneem te word, soos in die volgende hipotetiese artikel deur die inskrywingsreeks "AFK.: asb.":

as·se'blief $b w ., t w$. [AFK.: asb.] 'n woord waarmee 'n mens iets hoflik vra: Gee asseblief die suiker aan. ${ }^{\circ}$ Kom saam, asseblief.

\subsubsection{Ingevoegde binnetekste}

Ingevoegde binnetekste is reeds 'n algemene verskynsel in skoolwoordeboeke. Vergelyk die volgende voorbeeld met die opskrif "Spelling" na die artikel van die lemma lei ${ }^{2}$ in die HAT Skoolwoordeboek:

$\mathbf{l e i}^{1}$ en $\mathbf{l e i}^{2}$ is homonieme; lei en ly is homofone. Maak seker dat jy die verskil in spelling en betekenis ken.

Vanuit 'n leerdergerigte benadering sou betoog kon word vir inhoude wat nie bloot inligting voorsien nie, maar die leerder deur onder meer vraagstelling uitdaag om self ondersoek in te stel en te verken en sodoende 'n vennoot in die leerproses te word (vgl. 2.3). Ter ondersteuning hiervan sou die volgende herbewerking van bostaande inhoud voorgestel kon word:

$\mathbf{l e i}^{1}$ en lei $\mathbf{i}^{2}$ is homonieme; lei en ly is homofone. Wat is 'n homoniem? Wat is 'n homofoon? Wat is die verskil in betekenis tussen lei en ly?

Deur die inhoud vernuwend in die vorm van vrae aan te bied, neem die woordeboek self deel aan die stimulering van 'n leksikografies relevante inligtingsbehoefte by die leerder, en word leerdergerigte leer sowel as woordeboekgebruik bevorder. (Die veronderstelling is uiteraard dat die antwoorde op sodanige vrae in die betrokke woordeboek te vinde is.) 


\subsection{Perspektief op leksikografiese vernuwing}

Die elemente van vernuwing wat in die voorafgaande bespreking oorsigtelik aangebied is, verteenwoordig slegs enkele opsigte waarin skoolwoordeboeke vir 'n bepaalde konteks, soos dié van die onderwys in Namibië, funksioneel beplan kan word. Veral met die oog op leerdergerigte taalonderrig en WIT as ' $n$ belangrike skakel in die proses wat tot OWG en uiteindelik 'n IWK kan lei, is leksikografiese vernuwing gebaseer op verdere navorsing nodig.

\section{Slot}

Die kennisname van sillabusvereistes en die bestudering van handboeke is maar sommige van die aspekte wat ter sprake is wanneer 'n skoolwoordeboek beplan word. By die bestudering van sillabusse behoort nie slegs op die vereistes met betrekking tot woordeboekgebruik gefokus te word nie, maar leksikograwe kan volledige sillabusse deurwerk en hulleself ten opsigte van elke doelstelling en doelwit afvra: Kan die skoolwoordeboek 'n datakategorie akkommodeer wat kan bydra tot die bereiking van hierdie doelstelling of doelwit?

Afgesien van sillabusse moet ander sistemiese faktore as die produkte van die konteks waarbinne woordeboekgebruik plaasvind, deeglik in skoolwoordeboekbeplanning verreken word. Hierdie eis veronderstel dat die leksikograaf in die beplanning van 'n skoolwoordeboek die nodige kundigheid deur aktiewe konsultasie met belanghebbendes bekom en dat die woordeboek uiteindelik 'n produk van spanwerk tussen 'n verskeidenheid kundiges eerder as van die werk van 'n enkele leksikograaf sal wees (vgl. Gouws 2006). Wanneer die vraag "Wat hoort in 'n skoolwoordeboek?" gevra word, gaan dit dus nie bloot oor wátter data aangebied kan word nie, maar ook oor hóé die data aangebied kan word.

Volgens Bogaards (2003: 28) bestaan daar byna geen navorsing oor woordeboekgebruik deur moedertaalleerders nie. Ten einde meer funksionele skoolwoordeboeke tot stand te bring, sal hierdie beduidende leemte daadwerklik oorkom moet word.

Daar is al gesê dat woordeboeke nie alles vir almal kan wees nie. Wat skoolwoordeboeke betref, kan dit nietemin die leksikograaf se ideaal wees dat die innoverende onderwyser wat oor die regte leestekste vir sy klas en 'n stel optimaal funksionele skoolwoordeboeke beskik, geen ander bron sal benodig om die leerplan suksesvol te dek nie.

\section{Notas}

1. Hierdie verwarring kan vererger word deur die huidige gebruik van die term leerder in plaas van die vroeëre leerling in onderwysgeledere. Veral in Engels, waar die term learner gevolglik 
polisemies (en semanties divergent ten opsigte van Afrikaans se aanleerder en leerder) is, sou die frase "learner's dictionary" in die titel van 'n Suid-Afrikaanse woordeboek na óf 'n aanleerderwoordeboek óf 'n skoolwoordeboek met 'n gepersonifiseerde titel kon verwys.

2. Woordeboekgebruik kan ook as 'n kommunikatiewe handeling beskou word (vgl. Beyer 2006).

3. Vergelykings word wel in die mikrostruktuur van die HAT Skoolwoordeboek aangebied, maar nie op konsekwente wyse nie, bv. nie in die artikel van die lemma arm nie, maar wel (as "spreekwoord" aangedui) in dié van vark.

\section{Bronnelys}

\section{Primêre literatuur (woordeboeke)}

Gouws, R.H., M. Stark en L. Gouws. 2004. Nuwe woordeboek sonder grense. Kaapstad: Maskew Miller Longman.

Gouws, R., L. Potgieter en S. Burgess. 2010. Longman Grondslagfasewoordeboek Afrikaans/Engels. Kaapstad: Maskew Miller Longman.

Hartmann, R.R.K. en G. James. 1998. Dictionary of Lexicography. Londen/New York: Routledge.

Louw, P. (Red.). 2007. Oxford Afrikaans-Engels/English-Afrikaans Skoolwoordeboek/School Dictionary. Kaapstad: Oxford University Press Southern Africa.

Luther, J. (Red.). 2009. HAT Afrikaanse skoolwoordeboek. Pinelands: Pearson Education South Africa.

Luther, J. 2010. HAT Aktiwiteite en speletjies by die Afrikaanse skoolwoordeboek en Afrikaanse sakwoordeboek. Pinelands: Pearson Education South Africa.

Oxford University Press Southern Africa. 2006. South African Oxford Secondary School Dictionary. Kaapstad: Oxford University Press Southern Africa.

Taalkommissie van die Suid-Afrikaanse Akademie vir Wetenskap en Kuns. 2009. Afrikaanse woordelys en spelreëls. Kaapstad: Pharos.

\section{Sekondêre literatuur}

Béjoint, H. 1989. The Teaching of Dictionary Use: Present State and Future Tasks. Hausmann, F.J., O. Reichmann, H.E. Wiegand en L. Zgusta (Reds.). 1989-1991. Wörterbücher. Ein internationales Handbuch zur Lexikographie/Dictionaries. An International Encyclopedia of Lexicography/ Dictionnaires. Encyclopédie internationale de lexicographie: 208-215. Berlyn/New York: Walter de Gruyter.

Beyer, H.L. 2006. 'n Voorlopige model vir die sistematiese beskrywing van gebruikersvriendelikheid in woordeboeke. Lexikos 16: 46-66.

Bogaards, P. 2003. Uses and Users of Dictionaries. Van Sterkenburg, P. (Red.). 2003. A Practical Guide to Lexicography: 26-33. Amsterdam/Philadelphia: John Benjamins.

Carstens, A. 1995. Language Teaching and Dictionary Use: An Overview. Lexikos 5: 105-116.

Combrink, L., N. Faasen, H. Geyser en A. Kloppers. 1997. Taalkonteks. Kenwyn: Juta.

De Schryver, G., D. Joffe, P. Joffe en S. Hillewaert. 2006. Do Dictionary Users Really Look Up Frequent Words? - On the Overestimation of the Value of Corpus-based Lexicography. Lexikos 16: 67-83. 
Gouws, R.H. 1989. Leksikografie. Pretoria/Kaapstad: Academica.

Gouws, R.H. 2006. Leerdergedrewe leksikografie. Tydskrif vir Taalonderrig 40(1): 72-84.

Gouws, R.H. 2009. Geïntegreerde woordeboekgebruik van vakwoordeboeke vir aanleerders. Lexikos 19: 72-93.

Gouws, R.H. en D.J. Prinsloo. 2005. Principles and Practice of South African Lexicography. Stellenbosh: SUN PReSS.

Gouws, R.H. en S. Tarp. 2008. A New Step Forward for South African Learners' Lexicography: The Oxford Afrikaans-Engels/English-Afrikaans Skoolwoordeboek/School Dictionary. Tydskrif vir Taalonderrig 42(1): 65-79.

Hartmann, R.R.K. 2001. Teaching and Researching Lexicography. Essex: Pearson Education.

Hausmann, F.J. 1977. Einführung in die Benutzung der neufranzösischen Wörterbücher. Tübingen: Niemeyer.

Hiles, L. 2010. Examples in South African School Dictionaries: From Theory to Practice. Ongepubliseerde M.Phil.-tesis. Stellenbosch: Universiteit Stellenbosch.

Jackson, H. 2002. Lexicography. An Introduction. London/New York: Routledge.

Kernerman, I.J. 2007. What's So Good or Bad about Advanced EFL Dictionaries? Gottlieb, H. en J.E. Mogensen (Reds.). 2007. Dictionary Visions, Research and Practice. Selected Papers from the 12th International Symposium on Lexicography, Copenhagen 2004: 139-145. Amsterdam/Philadelphia: John Benjamins.

Lombard, F.J. 1990. 'n Metaleksikografiese fundering van Afrikaanse skoolwoordeboeke. Ongepubliseerde D.Litt.-proefskrif. Stellenbosch: Universiteit Stellenbosch.

Louw, P.A. 2004. Criteria for a Multifunctional, Monolingual Dictionary in Junior Secondary Education. Ongepubliseerde D.Litt.-proefskrif. Stellenbosch: Universiteit Stellenbosch.

Meij, K., T. Kühn, en R. Snyman. 1985. Vakdidaktiek: Afrikaans Moedertaal in die Sekondêre Skool. Pretoria: De Jager-HAUM.

Ministry of Basic Education and Culture. 1998. Pilot Curriculum Guide for Formal Senior Secondary Education. Okahandja: National Institute for Educational Development.

Ministry of Basic Education and Culture. 2000. Upper Primary Phase First Language Syllabus: Afrikaans. Grades 5-7. Okahandja: National Institute for Educational Development.

Ministry of Basic Education, Sport and Culture. 1996. Pilot Curriculum Guide for Formal Basic Education. Okahandja: National Institute for Educational Development.

Ministry of Basic Education, Sport and Culture. 2004. The Curriculum for the Lower Primary Phase (Grades 1-4). Okahandja: National Institute for Educational Development.

Ministry of Education. 2005. Lower Primary Phase Syllabus Guide. English First Language Grades 1-4. Okahandja: National Institute for Educational Development.

Ministry of Education. 2006. Namibia Senior Secondary Certificate Ordinary Level (NSSCO) Afrikaans First Language Syllabus. Grades 11-12. Okahandja: National Institute for Educational Development.

Ministry of Education. 2006a. Namibia Senior Secondary Certificate Higher Level (NSSCH) Afrikaans First Language Syllabus. Grades 11-12. Okahandja: National Institute for Educational Development.

Ministry of Education. 2007. Junior Secondary Phase Afrikaans First Language Syllabus. Grades 8-10. Okahandja: National Institute for Educational Development. 
Ministry of Education. 2008. National Subject Policy Guide: English First Language Grades 5-12. Okahandja: Ministry of Education.

Ministry of Education and Culture. 1993. The Language Policy for Schools. 1992-1996 and Beyond. Windhoek: Ministry of Education and Culture.

NIED. 2003. Learner-Centred Education in the Namibian Context: A Conceptual Framework. Okahandja: National Institute for Educational Development.

Tarp, S. 2008. Lexicography in the Borderland between Knowledge and Non-Knowledge. General Lexicographical Theory with Particular Focus on Learner's Lexicography. Lexicographica. Series Maior 134. Tübingen: Max Niemeyer.

Tarp, S. en R.H. Gouws. 2008. A Lexicographic Approach to Language Policy and Recommendations for Future Dictionaries. Lexikos 18: 232-255.

Van der Merwe, M.F. 2009. Die opvoedkundige waarde van woordeboeke: Voorstelle vir woordeboekonderrig in Suid-Afrika. Lexikos 19: 297-313. 